\title{
Recurrent spontaneous haemarthrosis of the knee associated with a synovial and juxta-articular haemangiohamartoma
}

\author{
Tuomo Visuri
}

\begin{abstract}
Several spontaneous episodes of haemarthroses of the knee in a young man led to repeated arthroscopic examinations and one arthrotomy of the affected joint until a juxtaarticular haemangiohamartoma was indicated by angiogram. Excision of the malformation stopped the bleeding tendency.
\end{abstract}

Traumatic haemarthrosis of the knee joint is common and currently the intra-articular causes of bleeding can be accurately diagnosed by arthroscopy. A spontaneous haemarthrosis of the knee joint is rare and is usually due to haemophilia." Vascular tumours and malformations are other, more uncommon causes. There are two forms of vascular tumour of the legs-namely, true haemangiomas and arteriovenous malformations or haemangiohamartomas, which may both involve the synovium and cause spontaneous intra-articular bleeding.

In this article a case of juxta-articular haemangiohamartoma with a synovial extension associated with a haemorrhagic synovitis and recurrent spontaneous haemarthroses is reported.

\section{Case report}

A 24 year old man sustained a haemarthrosis of the right knee while playing volleyball without any accident (November 1984). He had had varicose veins and hypertrophy of his right lower leg since childhood. At the age of 17 he underwent a successful operation for varicose veins. Apart from haemarthrosis the knee joint was normal clinically, radiologically, and in an arthrographic examination. The leg was lengthened by $2.5 \mathrm{~cm}$ and the circumference of the calf increased by $2 \mathrm{~cm}$.

Between January 1986 and March 1986 the patient sustained three spontaneous haemarthroses of the knee. In January 1985 he underwent arthroscopy of the knee. The lateral part of the suprapatellar recess was thickened and uneven. Haemangiomatous tissue was suspected in this area, which was resected by an open arthrotomy. In the histological examination the synovium was recently thickened and covered by loose granulation tissue, under which were found both recent and old haemor-

Central Military Hospital, Mannerheimintie 164, 00301 Helsinki, Finland Tuomo Visuri

Accepted for publication 25 August 1989 rhagic changes, particularly around a large artery-type vessel. In the basal layer the synovium was rich capillary haemangiomatous tissue (fig 1A). At this stage the histological diagnosis was haemorrhagic synovitis.
The patient's blood was analysed for any coagulation disorder. All tests were normal. Liver function tests were also normal.

In October 1985 arthrography and arthroscopy were performed again, but the bleeding point could not be verified.

In February 1986 an angiographic examination around the knee was performed. An arterial phase was normal (fig $2 \mathrm{~A}$ ), but in the venous phase a collection of dye in small loculi was noted in the proximal and medial part of the knee (fig 2B).

In June 1986 the vascular tumour was excised. It was located subcutaneously in an area between the vastus medialis and hamstring muscles, which consisted of a $3 \mathrm{~cm}$ collection of venous plexuses. The histopathology of the tumour showed non-neoplastic partially angiovenous and partially capillary vascular malformation (figs 1B-E). Recovery from the operation was smooth and uneventful. The patient has been able to continue with normal military exercises and sports activities up to the present.

\section{Discussion}

In 1990 Klippel and Trenaunay described a syndrome characterised by osseous and soft tissue hypertrophy, varicose veins dating from infancy, and haemangioma of the skin. ${ }^{2}$ Since then there has been a confusing nomenclature for the vascular malformations of the legs: Parkes-Weber syndrome, ${ }^{3}$ muscle-skin angioma, diffuse angiomatosis, congenital arteriovenous fistula, and genuine diffuse phlebectasia. ${ }^{4}$ In the last reports no clear difference was made between true haemangiomas and haemangiohamartomas, both were reported under the name: haemangioma.

Goidanich and Campanacci studied 94 patients and classified the vascular malformations of the lower legs into six groups, the most common being localised deep vascular hamartomas in about half of the cases. ${ }^{4}$ The patient they presented had a typical subcutaneous vascular hamartoma as shown by its localisation, angiographic study, and histological findings. ${ }^{4}$

The first case of synovial haemangioma was described by Bouchluil in $1856 . .^{5}$ Since then over 100 cases have been reported. Most cases have been haemangiohamartomas and only a few true haemangiomas.

True haemangiomas are small, sessile or stalked lesions arising near the infrapatellar fat pad and must be distinguished from villonodular synovitis. Their maximum size is $0.8 \mathrm{~cm}$. Sometimes phleboliths are seen. Microscopic 

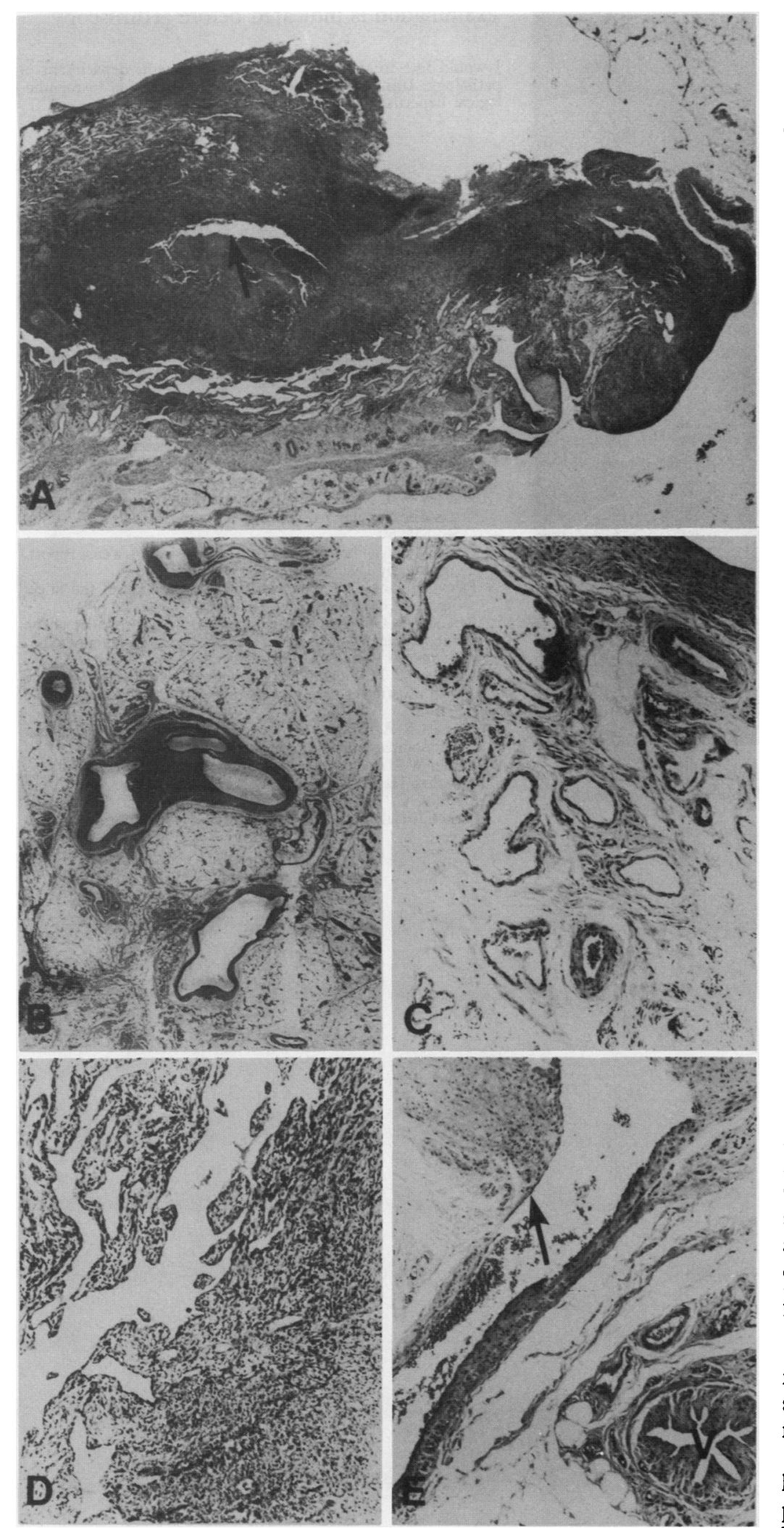

Figure 1: (A) Micrograph of the synovium of the knee. Haematoxylin and eosin staining. The synovium shows evidence of both old and recent haemorrhagic changes. Capillary

haemangiomatous tissue is shown in the basal layer of the synovia. A dilated and partially thrombotic, endothelium space (artery) (arrow) surrounded by haemorrhage and inflamed synovial tissue and granulation corresponds to a picture of haemorrhagic synovitis. ( $B$ and $C$ ) Micrograph of the angiomatous lesion. Low power view of the vascular lesion showing abnormal arteries, thick walled veins, and dilated capillaries in the loose connective tissue. (D) Capillary portion of the angiomatous lesion. $(E)$ An arteriovenous anastomosis (arrow) within the tissue shown in fig $I B$. An abnormal, thick-walled vein $(V)$ is seen in the lower, right hand corner.
Non-infectious, benign causes of spontaneous haemarthrosis of the knee

Haemophilia and associated conditions

Synovial haemangioma

Synovial and juxta-articular haemangiohamartoma

Kasabach-Merritt syndrome

Pigmented villonodular synovitis

'Chronic rupture of anterior cruciate ligament'

Chondrocalcinosis

examination shows that the haemangioma is usually cavernous, ${ }^{6}$ and occurs most often in childhood or in young adults. ${ }^{7}$

In addition to pain, swelling, and palpable mass, both the haemangiohamartoma and synovial haemagioma may cause spontaneous haemarthroses. Haemangioma was suspected in our patient, but despite two arthroscopies, two arthrograms, and one arthrotomy no synovial vascular tumour could be confirmed because the synovial extension of the tumour was basal and capillary and therefore not visible. Excision of the extra-articular part of the tumour cured the bleeding, however. The tumour may cause venous congestion of the synovium and haemorrhagic synovitis.

Arthroscopy has been recommended as a diagnostic tool. Without it small, stalked synovial haemangiomas especially, may not be diagnosed. Arthroscopy should be performed without tourniquet to detect the blood filled tumour and without a television which may change the characteristic dark colour of the haemangioma. ${ }^{89}$ With small haemangiomas the angiogram may be negative. ${ }^{8} \mathrm{~A}$ tourniquet was used in our case, which possibly made a proper diagnosis more difficult.

Spontaneous haemarthrosis itself is rare. It may be caused by infections or malignant tumours. The table lists benign, non-infectious causes.

The most common cause of spontaneous intra-articular bleeding is haemophilia, ${ }^{1}$ and the most common site the knee joint. Resnick and Oliphant described a case of Kasabach-Merritt syndrome associated with haemophilia-like arthropathy of the knee joint. ${ }^{10}$ This syndrome consists of extensive capillary haemangiomas, leading to consumption coagulopathy and bleeding tendency.

Pigmented villonodular synovitis is another rare cause of spontaneous haemarthrosis, ${ }^{11}$ sometimes accompanied by vascular malformation. ${ }^{12}$

Recurrent, post-traumatic, spontaneous haemarthroses of the knee may be due to a partial tear of the anterior cruciate ligament. When an initial trauma causing a partial tear of this ligament is followed by poor scar formation the ligament remains insufficient. Further tearing is accompanied by bleeding in the joint. Recurrent haemarthrosis is pathognomonic of a 'chronic cruciate ligament rupture'. ${ }^{13}$

Menkès and Rondier reported a series of 28 patients with haemarthrosis in 28 joints, including 20 knees. The haemarthroses were associated with chondrocalcinosis and joint destruction. 14 


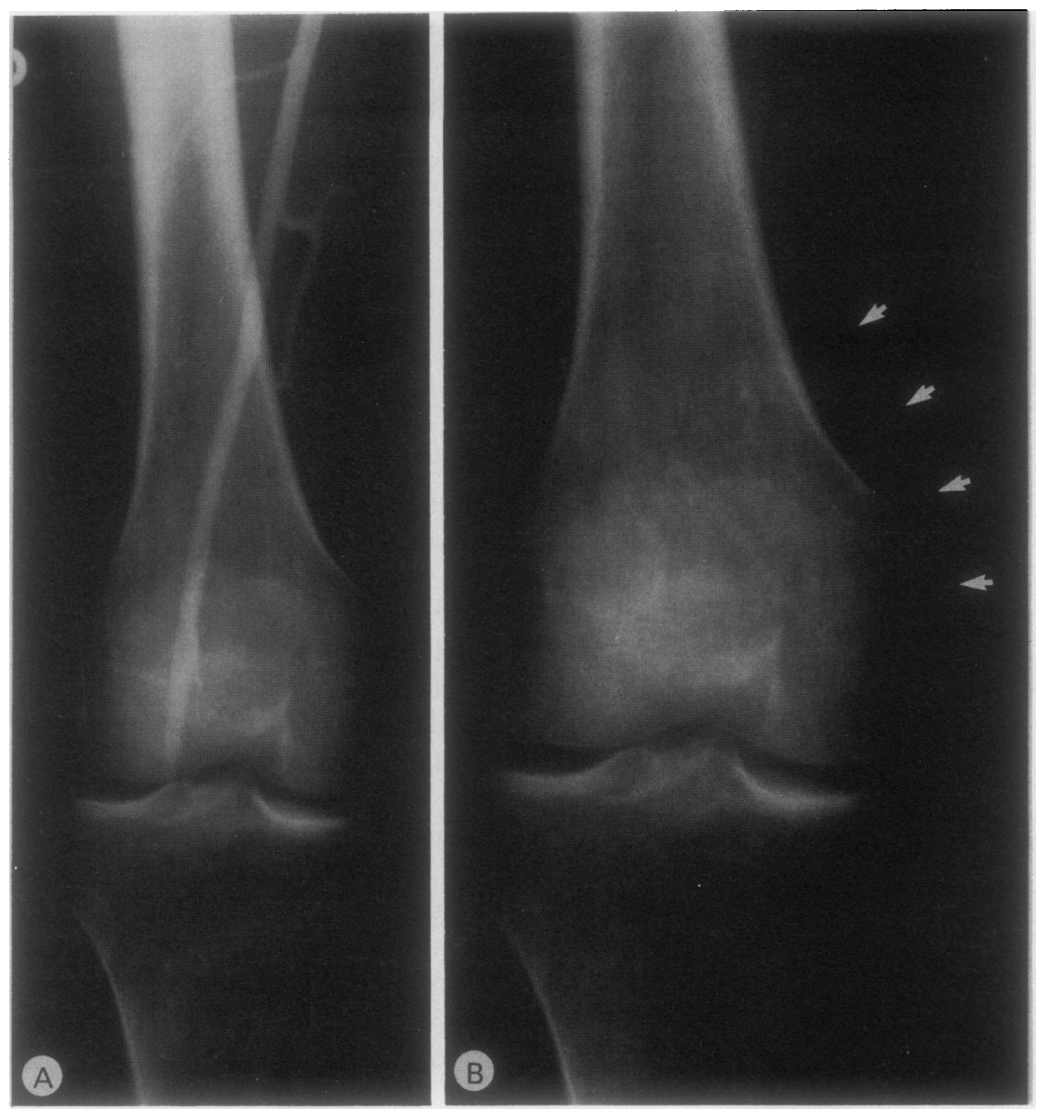

Figure 2: Angiogram. (A) The arterial phase of the angiogram is normal; $(B)$ the venous phase shows accumulations of dye in small loculi in the medial and proximal sites of the knee joint.
When vascular malformation is suspected in the spontaneous haemarthrosis an angiographic examination is indicated before arthroscopy.

I would like to thank Professor Lauri Saxem, department of pathology, University of Helsinki, for his help and histopathoogical expertise.

1 Steven M M, Yograjah S, Madhok R, Sturrock R D. Haemophilic arthritis. $Q f$ Med 1986; 58: $181-97$.

Klippel M, Trenaunay P. Du noevus variquex ostéohypertrophique. Archives Générales de Médicine 1900; 3: 641-72.

3 Parkes Weber F. Angioma-formation in connection with hypertrophy of limbs and hemi-hypertrophy. $\mathrm{Br} \mathcal{F}$ Dermatol 1907; 19: 231-5.

4 Goidanich I F, Campanacci M. Vascular hamartomata and infantile angioectatic osteohyperplasia of the extremities. f Bone foint Surg [Am] 1962; 44: 815-41.

5 Bouchluil $E$. Tumeur erectile de l'articulation du genou. Gazette des Hôpitaux Civils et Militaire (Paris) 1856; 29:

6 Schiller L. Tumor and tumor like lesions involving joints. In: Kelley W N, Harris E D Jr, Ruddy S, Sledge C B , eds. Textbook of rheumatology. 2nd ed. Philadelphia, London, Toronto, Mexico City, Rio de Janeiro, Sydney, Tokyo: Saunders, 1985: 1711-32.

7 Hawley W L, Ansell B M. Synovial hemangioma presenting as monoarticular arthritis of the knee. Arch Dis Child 1981; 56: 558-60.

8 Boe S. Synovial hemangioma of the knee joint-a case report. Arthroscopy 1986; 2: 178-80.

9 Paley D, Jackson R W. Synovial hemangioma of the knee: diagnosis by arthroscopy. Arthroscopy 1986; 2: 174-7.

10 Resnick D, Oliphant $M$. Hemophilia like arthropathy of the knee associated with cutaneous and synovial hemangioma. Radiology 1975; 323: 323-6.

11 Docken W P. Pigmented villonodular synovitis. A review with illustrative case reports. Semin Arthritis Rheum 1979; 9: 1-22.

12 Burnett R A. A cause of erroneous diagnosis of pigmented villonodular synovitis. $\mathcal{F}$ Clin Pathol 1976; 29: 17-21.

13 Müller W. The Knee, form, function and ligament reconstruction. Berlin, Heidelberg New York: Springer, 1983.

14 Menkès C J, Rondier J. Idiopathic haemarthrosis with chondrocalcinosis. Ann Rheum Dis 1987; 46: 85. 